\title{
SIMULTANEOUS ANTEGRADE AND RETROGRADE DELIVERY OF CONTINUOUS WARM BLOOD CARDIOPLEGIA AFTER GLOBAL ISCHEMIA
}

Anders B. Ericsson, MD

Shigeto Takeshima, MD

Jarle Vaage, MD, PhD
Objective: Simultaneous delivery of antegrade and retrograde cardioplegia may provide a more homogeneous distribution of cardioplegic solution. It may, however, increase myocardial edema and postcardioplegic myocardial injury. The purpose of this study was to compare simultaneous antegrade-retrograde cardioplegia with antegrade cardioplegia. Methods: After 30 minutes of warm, "unprotected," global ischemia, pigs were given warm, continuous blood cardioplegia for 45 minutes (antegrade group, $n=8$ and simultaneous antegrade-retrograde group, $n=9$ ). All pigs were weaned from cardiopulmonary bypass 45 to 60 minutes after aortic unclamping. Indices of left ventricular function were measured after another 30 minutes with the conductance catheter technique and pressure-volume loops. Results: Global left ventricular function, evaluated by preload recruitable stroke work, decreased from baseline values of 126 (102 to 150) (mean [90\% confidence limits]) (antegrade) and $122(116$ to 127$) \mathrm{erg} / \mathrm{ml} \times 10^{3}$ (simultaneous) to $75(61$ to 89$)(p=0.004)$ and 95 (79 to 112) $\mathrm{erg} / \mathrm{ml} \times 10^{3}(p=0.02)$, respectively. End-diastolic pressurevolume relation increased from $0.25(0.21$ to 0.28$)$ (antegrade) and $0.30(0.25$ to 0.35$) \mathrm{mm} \mathrm{Hg} / \mathrm{ml}$ (simultaneous) to $0.60(0.41$ to 0.79$)(p=0.009)$ and 0.53 $(0.35$ to 0.71$) \mathrm{mm} \mathrm{Hg} / \mathrm{ml}(p=0.02)$, respectively. The time constant of left ventricular pressure relaxation was unchanged. No intergroup difference was observed in preload recruitable stroke work, preload recruitable stroke work area, end-diastolic pressure volume relation, or stiffness constant. Plasma levels of troponin $\mathrm{T}$ increased without any difference between groups. Myocardial water content was increased in the simultaneous group $(81.1 \%$ [80.7\% to $81.5 \%$ ]) versus the antegrade group $(80.1 \%$ [79.6\% to $80.7 \%$ ], $p=$ 0.01). Conclusion: Despite a small increase in myocardial water content induced by simultaneous blood cardioplegia, no impairment of postcardioplegic cardiac function was observed compared with antegrade cardioplegia. (J Thorac Cardiovasc Surg 1998;115:716-22)
W ith antegrade cardioplegia, flow distal to coronary occlusions or critical stenoses may be compromised, causing inhomogeneous distribution

From the Department of Thoracic Surgery, Karolinska Hospital, 17176 Stockholm, Sweden.

This study was supported by grants from the Swedish Heart Lung Foundation, from the Swedish Medical Research Council (grant no. 11235), the Karolinska Institute, and from the Karolinska Hospital.

Received for publication Feb. 25, 1997; revisions requested May 7, 1997; revisions received Sept. 22, 1997; accepted for publication Sept. 22, 1997.

Address for reprints: Anders B. Ericsson, MD, Department of Thoracic Surgery, Karolinska Hospital, S-171 76, Stockholm, Sweden.

Copyright (C) 1998 by Mosby, Inc.

$0022-5223 / 98 \$ 5.00+0 \quad \mathbf{1 2 / 1 / 8 6 3 3 4}$ of the cardioplegic solution. ${ }^{1}$ Retrograde delivery through the coronary sinus in these situations is probably a superior route of administration. ${ }^{2-4} \mathrm{Un}$ fortunately, the distribution of retrograde cardioplegia is also inhomogeneous, ${ }^{5,6}$ and only $25 \%$ to $80 \%$ of retrograde cardioplegia appears to be nutritive. ${ }^{2,6-10}$ These problems of distribution may be overcome by combining antegrade and retrograde cardioplegia. The heart may be arrested with an initial dose of antegrade cardioplegia, with the subsequent doses given through the coronary sinus, or by alternating between antegrade and retrograde perfusion. ${ }^{11-14}$ Another technique to improve distribution of cardioplegic solution is to occlude the coronary sinus during antegrade delivery. ${ }^{15}$

To provide an optimal and fast distribution of cardioplegia, even in the presence of obstructed 
vessels, simultaneous antegrade-retrograde delivery has been proposed by Buckberg's group. ${ }^{16}$ This simultaneous technique is easy to use without any change from antegrade to retrograde or vice versa. With the theoretical potential for homogeneous distribution, the simultaneous antegrade-retrograde cardioplegia might be the optimal mode of cardioplegia delivery. However, several questions are raised: Is it a safe method? Will the microvascular hydrostatic pressure increase to such an extent that myocardial edema will cause deterioration of left ventricular function? ${ }^{17}$ This possibility is particularly relevant in situations with acute occlusions and ischemia, which would be an important indication for simultaneous antegrade-retrograde cardioplegia. Ischemic injury to the coronary endothelium and myocytes will increase microvascular permeability and cause myocardial edema, ${ }^{17}$ rendering the heart more susceptible to increased hydrostatic pressure during cardioplegia and reperfusion. Giving large quantities of cardioplegic solution might then further enhance myocardial edema. A recent study showed edema formation during continuous antegrade warm blood cardioplegia with subsequent reduced systolic function. ${ }^{18}$

The purpose of this study was to compare the effect of antegrade versus simultaneous antegraderetrograde, continuous, warm blood cardioplegia on postcardioplegic left ventricular function, release of troponin $\mathrm{T}$ as a biochemical marker of cardiomyocyte injury, and on myocardial water content. To maximally challenge any edema tendency a porcine model with 30 minutes of global, normothermic, "unprotected" ischemia followed by 45 minutes of cardioplegia was used.

\section{Materials and methods}

All animals received humane care in compliance with the guidelines from the United States National Institutes of Health regulating the care and use of laboratory animals (NIH Publication No. 86-23, revised 1985). The study was approved by the Ethics Committee for Animal Research at the Karolinska Institute, Stockholm, Sweden.

Anesthesia and surgical procedures. Pigs with a body weight of 42 (41 to 43) $\mathrm{kg}$ (mean [90\% confidence limits]) were premedicated with intramuscular ketamine hydrochloride $(20 \mathrm{mg} / \mathrm{kg})$ and atropine sulfate $(0.5 \mathrm{mg})$. Anesthesia was induced with intravenous sodium pentobarbital $(15 \mathrm{mg} / \mathrm{kg})$ and maintained by a continuous infusion of a "cocktail" ( $0.30 \mathrm{ml} / \mathrm{kg}$ per hour) containing $2 \mathrm{mg}$ fentanyl citrate, $25 \mathrm{mg}$ midazolam, and $24 \mathrm{mg}$ pancuronium bromide in a volume of $57 \mathrm{ml}$. The infusion was preceded by a bolus of $0.15 \mathrm{ml} / \mathrm{kg}$. The pigs were intubated and ventilated with a volume-cycled ventilator (Engström 300, Datex-Engström AB, Bromma, Sweden).
Table I. Content of cardioplegia solution mixed 1:4 with blood

\begin{tabular}{lcc}
\hline \multicolumn{1}{c}{ Component } & $\begin{array}{c}\text { High } \\
K^{+} \text {-solution }\end{array}$ & $\begin{array}{c}\text { Low } \\
K^{+} \text {-solution }\end{array}$ \\
\hline $\mathrm{KCl}(\mathrm{mmol})$ & 101 & 30 \\
$\mathrm{MgSO}_{4}(\mathrm{mmol})$ & 16 & 15 \\
$\mathrm{Glucose}^{5}$ ( gm $(\mathrm{mmol})$ & 28 & 28 \\
THAM $(\mathrm{mmol})$ & 20 & 20 \\
Normal $(0.9 \%)$ saline solution & 1000 & 1000 \\
$\quad$ to a volume of $(\mathrm{ml})$ & & \\
\hline
\end{tabular}

THAM, Tris hydroxymethyl-aminomethane (=Trometamol).

Catheters were inserted into the right femoral artery and vein for blood sampling, pressure monitoring, and drug and fluid administration. A catheter and a temperature probe were surgically introduced into the urinary bladder. An electrocardiogram was recorded by surface electrodes. A Swan-Ganz catheter (Baxter Healthcare Corp., Edwards Division, Santa Ana, Calif.) was placed in the pulmonary artery through the right external jugular vein for pressure monitoring, cardiac output measurements, and injections of hypertonic saline solution for parallel conductance calibrations (see appendix).

After median sternotomy, the pericardium was opened. A 5F transducer-tipped pressure catheter (Mikro-Tip, Millar Instruments Inc., Houston, Tex.) and a 7F, 12-pole conductance catheter (Cordis Webster, Baldvin Park, Calif.) with 9 or $7 \mathrm{~mm}$ spacing between the electrodes, depending on heart size, were introduced into the left ventricle through a stab wound in the apex. The tip of the conductance catheter was brought through the aortic valve. Proper position of the catheter was confirmed before each set of measurements by visual inspection of the individual segmental volume signals.

After heparinization (activated clotting time $>480$ seconds), the ascending aorta was cannulated for cardiopulmonary bypass $(\mathrm{CPB})$ with a $20 \mathrm{~F}$ arterial cannula. The venous return was through a $32 \mathrm{~F}$ two-stage cannula in the right atrium. CPB was instituted with a flow of 75 to 90 $\mathrm{ml} / \mathrm{kg}$ per minute with a roller pump (7400, Sarns Inc./3M Health Care, Ann Arbor, Mich.) and a membrane oxygenator (Maxima, Medtronic Blood System, Anaheim, Calif.) primed with Ringer's acetate solution. CPB was allowed to drift to $34^{\circ}$ to $36^{\circ} \mathrm{C}$. The left ventricle was vented by a $20 \mathrm{~F}$ catheter inserted through the mitral valve through the left atrial appendage and connected to the venous line for passive drainage. The hemiazygos vein, which in the pig connects with the great cardiac vein to form the coronary sinus, was ligated.

The ostium of the coronary sinus was dissected, and a suture with a tourniquet was placed around it in both groups. A retrograde cardioplegia catheter (Research Medical, Inc., Midvale, Utah), with its balloon removed, was transatrially introduced into the coronary sinus.

A cardioplegia cannula was inserted into the aortic root, with a side branch for pressure monitoring. In the group given simultaneous antegrade-retrograde cardioplegia the cardioplegia lines were connected by a Yconnector and perfused by a single pump head. Pressure 


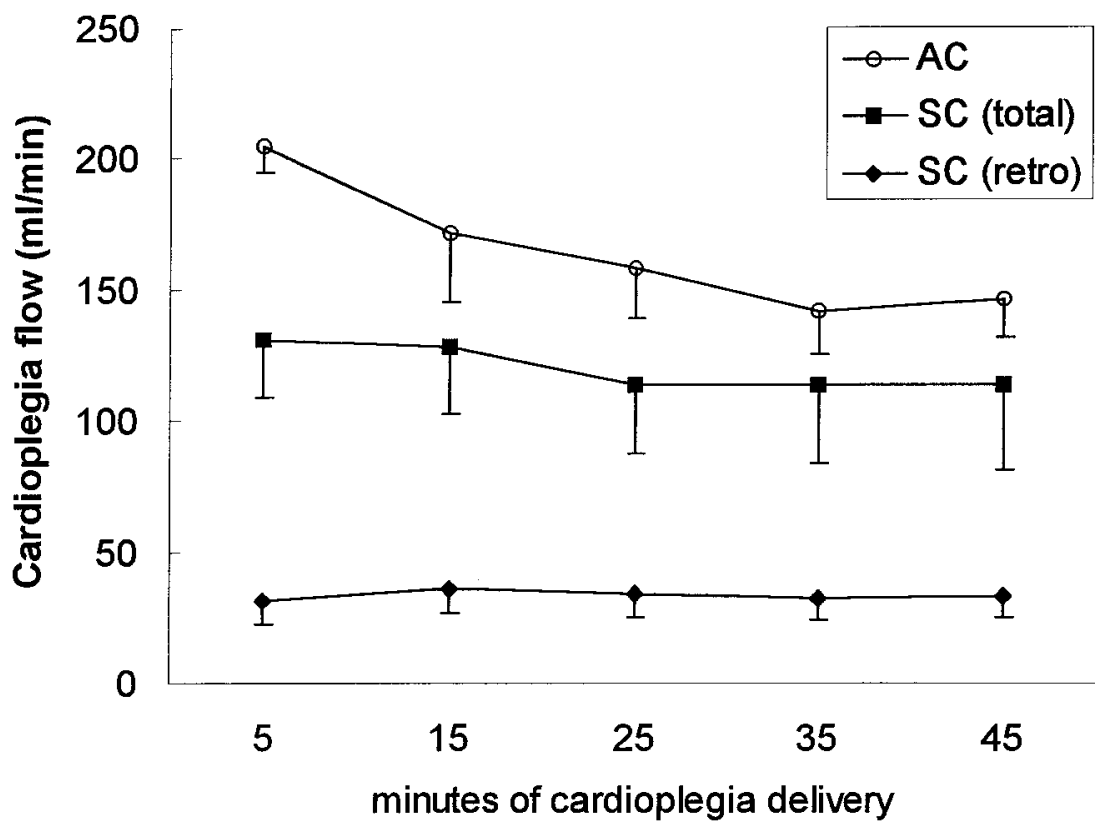

Fig 1. Cardioplegia flow in pigs given continuous warm blood cardioplegia for 45 minites after 30 minutes of unprotected ischemia in the antegrade $(A C)$ and simultaneous antegrade-retrograde $(S C)$ cardioplegia group. $S C$ (total) is total flow, and $S C$ (retro) is retrograde flow in the SC group. Data are presented as mean and a $-90 \%$ confidence limit. For $p$ values see text.

was measured both in the coronary sinus and in the aortic root. Total cardioplegia flow was continuously measured and displayed by the cardioplegia delivery pump. Retrograde flow was measured by an ultrasound transit-time flowmeter (CM 1000, CardioMed A/S, Oslo, Norway), with a flow probe on the cardioplegia tubing to the coronary sinus to measure the relative antegrade-retrograde distribution of cardioplegia flow.

Data acquisition. Hemodynamic and mechanical data were acquired during disconnection of the ventilation in end-expiration to minimize the effects of intrathoracic pressure variations. The mechanical data were acquired during variable loaded beats by occluding the inferior vena cava for 10 to 15 seconds. Every measurement was repeated at least three times, with a period of 2 minutes for circulatory stabilization between acquisitions.

The conductance catheter was connected to a Leycom Sigma-5 signal-conditioner processor (CardioDynamics BV, Zoetermeer, The Netherlands). The principle and technique for volume measurement have previously been presented in detail (see appendix). ${ }^{19,20}$ The volume signal was corrected to absolute volume by calibrating the signal for parallel conductance, to cardiac output measured by thermodilution, and to the specific conductivity of the blood (see appendix). The volume and pressure signals were processed (Conductance-PC software, Cardio-Dynamics BV, Zoetermeer, The Netherlands), and the left ventricular pressure-volume loops were displayed on-line and stored on the computer hard disk.
Data analysis and calculations

Hemodynamics. End-diastole was defined as the lower right-hand corner of the pressure-volume loop. Left ventricular end-diastolic pressure and volume were measured, and the stroke work was calculated as the area within the pressure-volume loop. The time constant of left ventricular isovolumic pressure relaxation $(\tau)$ was calculated as the time required for the left ventricular pressure at maximum negative $\mathrm{dp} / \mathrm{dt}$ to be reduced by half. ${ }^{21}$

Mechanical data. Global left ventricular function was quantitated by the slope $\left(\mathrm{M}_{\mathrm{w}}\right)$ of the preload recruitable stroke work relation $\left(\mathrm{PRSW}, \mathrm{erg} / \mathrm{ml} \times 10^{3}\right), \mathrm{V}_{0}$ (the $\mathrm{x}$-axis [volume] intercept of the PRSW) and the preload recruitable stroke work area (PRSWA, erg $\left.\times \mathrm{ml} \times 10^{6}\right)($ see appendix).22, 23

Left ventricular diastolic function was evaluated by the end-diastolic pressure volume relationship (EDPVR) and the stiffness constant ( $\beta$, see appendix).

Myocardial water content. Transmural samples of the left ventricular anterolateral wall were taken at the end of the experiment for measurements of wet weight/dry weight ratios. The water content (in percent) was determined by the following formula: $100 \times$ (wet weight - dry weight)/wet weight.

Troponin T. Troponin $\mathrm{T}$ concentrations in serum were analyzed with the second generation of cardiac troponin $\mathrm{T}$ enzyme-linked immunosorbent assay, ${ }^{24}$ using the Enzymun-Test troponin T (Boehringer Mannheim Corp., 
Table II. Hemodynamic data

\begin{tabular}{|c|c|c|c|c|c|c|}
\hline & \multicolumn{2}{|c|}{ Baseline (pre) } & \multicolumn{2}{|c|}{ After cardioplegia } & \multicolumn{2}{|c|}{$p$ Value } \\
\hline & Mean & $\begin{array}{l}C L \\
90 \%\end{array}$ & Mean & $\begin{array}{c}C L \\
90 \%\end{array}$ & $\begin{array}{l}\text { Within group } \\
\text { pre vs post }\end{array}$ & $\begin{array}{c}\text { Between groups/interaction: } \\
\text { group } \times \text { time }\end{array}$ \\
\hline \multicolumn{7}{|c|}{ Antegrade cardioplegia group } \\
\hline MAP & 100 & $92-109$ & 77 & $67-86$ & $<0.001$ & \\
\hline PAPs & 32 & $30-35$ & 43 & $40-45$ & $<0.001$ & \\
\hline EDP & 8 & $6-9$ & 10 & $7-13$ & 0.2 & \\
\hline $\mathrm{CO}$ & 3.4 & $2.8-4.0$ & 3.1 & $2.6-3.6$ & 0.4 & \\
\hline HR & 84 & $78-90$ & 131 & $118-144$ & $<0.001$ & \\
\hline EDV & 61 & $52-69$ & 63 & $48-77$ & 0.8 & \\
\hline SW & 4.3 & $3.5-5.1$ & 1.7 & $1.4-2.0$ & 0.001 & \\
\hline $\mathrm{EF}$ & 67 & $60-73$ & 41 & $33-49$ & $<0.001$ & \\
\hline$\tau$ & 34 & $32-37$ & 35 & $33-38$ & 0.7 & \\
\hline \multicolumn{7}{|c|}{ Simultaneous antegrade-retrograde cardioplegia group } \\
\hline MAP & 95 & $87-102$ & 75 & $64-86$ & 0.03 & $0.5 / 0.7$ \\
\hline PAPs & 29 & $25-33$ & 41 & $37-45$ & $<0.001$ & $0.3 / 0.5$ \\
\hline EDP & 7 & $6-8$ & 11 & $8-14$ & 0.02 & $0.9 / 0.5$ \\
\hline $\mathrm{CO}$ & 3.6 & 3.1-4.0 & 3.3 & $2.7-3.8$ & 0.4 & $0.6 / 1.0$ \\
\hline HR & 85 & $77-93$ & 139 & 129-149 & $<0.001$ & $0.4 / 0.4$ \\
\hline EDV & 60 & $49-71$ & 50 & $42-58$ & 0.2 & $0.3 / 0.3$ \\
\hline SW & 4.0 & $3.5-4.5$ & 1.7 & $1.4-1.9$ & $<0.001$ & $0.7 / 0.7$ \\
\hline $\mathrm{EF}$ & 68 & $64-71$ & 47 & $37-58$ & 0.01 & $0.4 / 0.5$ \\
\hline$\tau$ & 37 & $34-39$ & 33 & $29-37$ & 0.2 & $1.0 / 0.2$ \\
\hline
\end{tabular}

$M A P$, Mean arterial pressure ( $\mathrm{mm} \mathrm{Hg}$ ); $P A P S$, systolic pulmonary arterial pressure $(\mathrm{mm} \mathrm{Hg}) ; E D P$, end-diastolic left ventricular pressure ( $\mathrm{mm} \mathrm{Hg}$ ); $C O$, cardiac output (L/min); $H R$, heart rate (beats/min); $E D V$, end-diastolic left ventricular volume $(\mathrm{ml}) ; S W$, stroke work (erg $\left.\times 10^{6}\right) ; E F$, ejection fraction $(\%)$; $\tau=$ time constant of isovolumic pressure relaxation (msec).

Indianapolis, Ind.). The plasma was stored at $-70^{\circ} \mathrm{C}$, and all samples were analyzed at the same time.

Experimental protocol. Pigs were randomized to antegrade $(n=8)$ or simultaneous antegrade-retrograde $(n=$ 9) continuous warm $\left(35^{\circ}\right.$ to $\left.36^{\circ} \mathrm{C}\right)$ blood cardioplegia.

Baseline hemodynamic and mechanical data were recorded before cannulation for CPB. Totally vented CPB was started, and troponin $\mathrm{T}$ was sampled concurrently in coronary sinus and arterial blood. During sampling the coronary sinus tourniquet was temporarily tightened to avoid admixture by right atrial blood. Then the aorta was clamped, and after 30 minutes of "unprotected" global, normothermic ischemia, cardioplegia was started with an initial dose of $500 \mathrm{ml}$ of high-potassium cardioplegia, followed by low-potassium cardioplegia (Table I). In the simultaneous group the coronary sinus tourniquet was tightened to prevent backflow of cardioplegic solution into the right atrium during infusion. Cardioplegic flow was continuously adjusted in the antegrade group to maintain an aortic root pressure of 70 to $80 \mathrm{~mm} \mathrm{Hg}$. In the simultaneous group flow was adjusted to a pressure in the coronary sinus (and thus also in the aortic root) of 40 to 45 $\mathrm{mm} \mathrm{Hg}$. Pressure and flow of cardioplegic infusion were registered after $5,15,25,35$, and 45 minutes of delivery. If the heart started to fibrillate, high-potassium cardioplegia was reintroduced until total arrest. After 45 minutes, cardioplegic infusion was stopped, the aorta unclamped, and rewarming begun. The left ventricular vent was discontinued 30 minutes after unclamping. After 45 minutes of reperfusion, arterial and coronary sinus blood samples were drawn for troponin $\mathrm{T}$ measurements, and the coronary sinus catheter was removed. Between 45 and 60 minutes after unclamping all pigs were weaned off CPB and decannulated. No inotropic support was ever used. After 90 minutes of reperfusion, hemodynamic and mechanical data were obtained, and troponin $\mathrm{T}$ was sampled in arterial blood. At the end of the experiment the pigs were given a lethal intravenous injection of pentobarbital and potassium.

Statistical analysis. All data are reported as mean and $90 \%$ confidence limits. For within group comparisons one-way ANOVA with repeated measures was used, and for between groups two-way ANOVA with repeated measures was used (Statistica, StatSoft Inc., Tulsa, Okla.).

\section{Results}

Cardioplegia and hemodynamics. Cardioplegia flow was higher in the antegrade than in the simultaneous antegrade-retrograde group $(p=0.03)$ (Fig. $1)$. In the antegrade group cardioplegia flow declined from 205 (195 to 215) $\mathrm{ml} / \mathrm{min}$ after 5 minutes of infusion to 147 (132 to 161$) \mathrm{ml} / \mathrm{min}$ after 45 minutes of infusion (Fig. 1, $p=0.001$ ). In the antegrade-retrograde group cardioplegia flow declined less with time: from 131 (109 to 152$)$ to 113 (82 to 145$) \mathrm{ml} / \mathrm{min}(p=0.03)$, and the difference between groups changed with time $(p=0.003$ for group $\times$ time interaction) (Fig. 1). In the retrograde-antegrade group $28 \%$ (25\% to $31 \%$ ) of total 
Table III. Mechanical data

\begin{tabular}{|c|c|c|c|c|c|c|}
\hline & \multirow{2}{*}{\multicolumn{2}{|c|}{ Baseline (pre) }} & \multirow{2}{*}{\multicolumn{2}{|c|}{ After cardioplegia }} & \multicolumn{2}{|c|}{$p$ Values } \\
\hline & & & & & \multirow[b]{2}{*}{ Within group pre vs post } & \multirow{2}{*}{$\begin{array}{c}\text { Between groups/interaction: } \\
\text { group } \times \text { time }\end{array}$} \\
\hline & Mean & CL $90 \%$ & Mean & CL $90 \%$ & & \\
\hline \multicolumn{7}{|c|}{ Antegrade cardioplegia group } \\
\hline $\mathrm{M}_{\mathrm{w}}$ & 126 & $102-150$ & 75 & $61-89$ & 0.004 & \\
\hline $\mathrm{V}_{0}$ & 16 & $13-20$ & 31 & $20-43$ & 0.07 & \\
\hline PRSWA & 198 & $164-232$ & 77 & $53-101$ & $<0.001$ & \\
\hline $\mathrm{E}_{\mathrm{ed}}$ & 0.25 & $0.21-0.28$ & 0.60 & $0.41-0.79$ & 0.009 & \\
\hline$\beta$ & 66 & $50-82$ & 108 & 61-154 & 0.2 & \\
\hline \multicolumn{7}{|c|}{ Simultaneous antegrade-retrograde cardioplegia group } \\
\hline $\mathrm{M}_{\mathrm{w}}$ & 122 & $116-127$ & 95 & $79-112$ & 0.02 & $0.4 / 0.1$ \\
\hline $\mathrm{V}_{0}$ & 21 & $16-26$ & 29 & $22-36$ & 0.1 & $0.7 / 0.4$ \\
\hline PRSWA & 168 & $144-193$ & 99 & $73-125$ & 0.01 & $0.8 / 0.07$ \\
\hline $\mathrm{E}_{\mathrm{ed}}$ & 0.30 & $0.25-0.35$ & 0.53 & $0.35-0.71$ & 0.02 & $0.9 / 0.4$ \\
\hline$\beta$ & 80 & $66-94$ & 84 & $62-107$ & 0.6 & $0.7 / 0.2$ \\
\hline
\end{tabular}

$M_{w}$, Slope of preload recruitable stroke work $\left(\mathrm{erg} / \mathrm{ml} \times 10^{3}\right) ; V_{o}=\mathrm{x}$-axis intercept $(\mathrm{ml}) ; P R S W A$, preload recruitable stroke work area $\left(\right.$ erg $\left.\times \mathrm{ml} \times 10^{6}\right)$; $E_{e d}$ Slope of end-diastolic pressure-volume relation $(\mathrm{mm} \mathrm{Hg} / \mathrm{ml}) ; \beta$, the stiffness constant $\left(\times 10^{-3}\right)$.

cardioplegia flow was directed to the coronary sinus, and this ratio did not change over time (Fig. $1)$.

No difference was observed between the groups in baseline or postcardioplegic hemodynamics (Table II).

Left ventricular function. PRSW and PRSWA decreased after ischemia and cardioplegia. PRSWA had a tendency to be better maintained in the simultaneous group (group $\times$ time interaction: $p=$ 0.07 , Table III), but no difference was found between the groups. EDPVR, but not $\beta$ and $\tau$ increased significantly after cardioplegia in both groups (Tables II and III). No difference was found in EDPVR, $\beta$ or $\tau$ between groups.

Tissue water content. After 90 minutes of reperfusion, the myocardial water content was higher in the simultaneous than in the antegrade group: $81.1 \%(80.7 \%$ to $81.5 \%)$ versus $80.1 \%$ ( $79.6 \%$ to $80.7 \%)(p=0.01)$.

Troponin T. Baseline troponin $\mathrm{T}$ concentration in arterial blood was 0.45 (0.26 to 0.63$)$ and 0.64 $(0.42$ to 0.86$) \mu \mathrm{g} / \mathrm{L}$ in the antegrade and antegraderetrograde group, respectively. It increased in both groups after 45 and 90 minutes of reperfusion to 11.0 (6.1 to 16.0$)$ and 14.1 (8.4 to 19.7$) \mu \mathrm{g} / \mathrm{L}$ at 90 minutes, respectively ( $p=0.005$ and $p=0.002)$, but without any difference between groups $(p=0.4)$. The concentration of troponin $\mathrm{T}$ was higher in the coronary sinus than in arterial blood after 45 minutes of ischemia $(p=0.001)$, but without any intergroup difference $(p=0.8)$.

\section{Discussion}

In both experimental groups an ischemic insult was induced with cardiac dysfunction and increased release of troponin T. By use of indices of cardiac function relatively insensitive to preload and afterload, we did not observe any difference in global left ventricular function, diastolic function, or hemodynamic variables between the groups after ischemia and cardioplegia. Neither was a difference in troponin $\mathrm{T}$ release detected. Consequently, the simultaneous delivery did not induce any additional myocardial damage compared with antegrade cardioplegia, despite a small increase in myocardial water content.

The present model mimics the use of continuous, warm blood cardioplegia as resuscitation of the myocardium after an acute coronary occlusion and myocardial infarction. The difference is that we challenged the whole myocardium, and global events in this study illustrate regional events in the clinical setting. In the experimental situation, unless an infarct is created that allows for quantification of its size, it is easier and more reliable to evaluate myocardial dysfunction and injury in the whole heart. Another reason to use an initial "unprotected" ischemia is that it maximally "challenges" the myocardium, and thus shortens by several hours the length of cardioplegia and time on CPB necessary to obtain a significant reduction of postcardioplegic function. Consequently, the animals are kept in better general condition with improved experimental conditions. 
This study did not demonstrate any significant advantage of simultaneous cardioplegia over the antegrade technique. This was not to be expected because antegrade cardioplegia provides adequate myocardial protection in the absence of critical coronary stenoses. However, even in a coronary circulation without critical stenoses, antegrade and retrograde delivery of cardioplegic solution may perfuse complementary vascular beds, and thus optimize myocardial distribution. ${ }^{14,25,26}$

The mean cardioplegia flow in the antegrade group was higher than in the antegrade-retrograde group. The explanation for this difference is probably the higher perfusion pressure of antegrade cardioplegia. To achieve a clinically relevant model the cardioplegia pressure in the antegrade group was set to 70 to $80 \mathrm{~mm} \mathrm{Hg}$. In the antegrade-retrograde group, cardioplegic solution was delivered by one pump head and through a Y-connection, and the coronary sinus pressure (40 to $45 \mathrm{~mm} \mathrm{Hg}$ ) was the perfusion pressure for the total cardioplegia flow. This setup is simple, easy, and convenient to use in the operating room. In a study on explanted human hearts, antegrade cardioplegia with a perfusion pressure of $80 \mathrm{~mm} \mathrm{Hg}$ was infused simultaneously with retrograde cardioplegia at a pressure of $40 \mathrm{~mm}$ $\mathrm{Hg}$, and still approximately $30 \%$ of capillary flow was found to be the contribution of retrograde cardioplegia. ${ }^{26}$

Our study demonstrated a small increase in water content in the simultaneous group. The water content in the hearts in our study is in agreement with previous findings in isolated, perfused pig hearts (about $80 \%$ ). ${ }^{27}$ In dogs subjected to global ischemia and reperfusion myocardial water content increased from $82 \%$ to $84 \% .{ }^{17}$ Theoretically myocardial edema per se would reduce cardiac function. In isolated pig hearts edema shifted the EDPVR of the left ventricle to the left, and significantly increased the stiffness constant. ${ }^{27}$ Even if simultaneous cardioplegia may be safe in the "nonischemic" myocardium, ${ }^{16}$ the anticipated increase in microvascular hydrostatic pressures might be deleterious to the myocardium already injured by acute ischemia. In the comparison of antegrade versus simultaneous antegrade-retrograde cardioplegia we wanted to maximally "challenge" the myocardium. The method with 30 minutes of unprotected ischemia before 45 minutes of simultaneous antegrade-retrograde cardioplegia given continuously is a very strong edemagenic insult. The tendency to induce edema is probably considerably less when simulta- neous cardioplegia is given intermittently rather than continuously.

Because of considerable intragroup variations, experimental groups consisting of eight and nine animals have a rather low statistical power, and clinically relevant differences may remain undetected. Therefore the results must be interpreted with caution. However, we still believe that simultaneous antegrade and retrograde blood cardioplegia is safe. Indeed, if any finding remained undetected, it might be that the simultaneous administration was the best one because PRSW and PRSWA tended to change less in the simultaneous group. In an initial clinical study consisting of 155 patients given simultaneous cardioplegia, no adverse effects were observed. ${ }^{16}$

To summarize, despite a small increase in myocardial water content, this study did not demonstrate any adverse effect on myocardial function by simultaneous blood cardioplegia. We believe that simultaneous cardioplegia is convenient and has the potential of being the optimal technique of cardioplegia delivery.

The invaluable assistance by chief perfusionist Ove Johansson and the perfusionist team of the Department of Thoracic Surgery, Karolinska Hospital, is gratefully acknowledged.

\section{REFERENCES}

1. Hilton CJ, Teubl W, Acker M, et al. Inadequate cardioplegic protection with obstructed coronary arteries. Ann Thorac Surg 1979;28:323-34.

2. Partington MT, Acar C, Buckberg GD, Julia PL, Kofsky ER, Bugyi HI. Studies of retrograde cardioplegia. I. Capillary blood flow distribution to myocardium supplied by open and occluded arteries. J Thorac Cardiovasc Surg 1989;97:605-12.

3. Haan C, Lazar HL, Bernhard S, Rivers S, Zallnick J, Shemin RJ. Superiority of retrograde cardioplegia after acute coronary occlusion. Ann Thorac Surg 1991;51:408-12.

4. Menasché P, Subayi J-B, Veyssié L, Le Dref O, Chevret S, Piwnica A. Efficacy of coronary sinus cardioplegia in patients with complete coronary artery occlusions. Ann Thorac Surg 1991;51:418-23.

5. Gates RN, Laks H, Drinkwater DC, et al. The microvascular distribution of cardioplegic solution in the piglet heart: retrograde versus antegrade delivery. J Thorac Cardiovasc Surg 1993;105:845-53.

6. Caldarone CA, Krukenkamp IB, Misare BD, Levitsky S. Perfusion deficits with retrograde warm blood cardioplegia. Ann Thorac Surg 1994;57:403-6.

7. Solorzano J, Taitelbaum G, Chiu C-JR. Retrograde coronary sinus perfusion for myocardial protection during cardiopulmonary bypass. Ann Thorac Surg 1978;25:201-8.

8. Gates RN, Laks H, Drinkwater DC, et al. Gross and microvascular distribution of retrograde cardioplegia in explanted human hearts. Ann Thorac Surg 1993;56:410-7.

9. Carrier M, Grégoire J, Khalil A, Thai P, Latour J-G, Pelletier 
LC. Myocardial distribution of retrograde cardioplegic solution assessed by myocardial thallium 201 uptake. J Thorac Cardiovasc Surg 1994;108:1115-8.

10. Ardehali A, Laks H, Drinkwater DC Jr, Gates RN, Kaczer E. Ventricular effluent of retrograde cardioplegia in human hearts has traversed capillary beds. Ann Thorac Surg 1995; 60:78-83.

11. Partington MT, Acar C, Buckberg GD, Julia PL. Studies of retrograde cardioplegia. II. Advantages of antegrade/retrograde cardioplegia to optimize distribution in jeopardized myocardium. J Thorac Cardiovasc Surg 1989;97:613-22.

12. Drinkwater DC Jr, Cushen CK, Laks H, Buckberg GD. The use of combined antegrade-retrograde infusion of blood cardioplegic solution in pediatric patients undergoing heart operations. J Thorac Cardiovasc Surg 1992;104:1349-55.

13. Hayashida N, Ikonomidis JS, Weisel RD. Adequate distribution of warm cardioplegic solution. J Thorac Cardiovasc Surg 1995;110:800-12.

14. Aldea GS, Hou D, Fonger JD, Shemin RJ. Inhomogeneous and complementary antegrade and retrograde delivery of cardioplegic solution in the absence of coronary artery obstruction. J Thorac Cardiovasc Surg 1994;107:499-504.

15. Sun S-C, Diaco M, Couper GS, Masetti P, Laurence RG, Cohn LH. Improved distribution of antegrade cardioplegic solution with simultaneous coronary sinus occlusion following acute coronary artery occlusion. J Surg Res 1992;53:98102.

16. Ihnken K, Morita K, Buckberg GD, et al. The safety of simultaneous arterial and coronary sinus perfusion: experimental background and initial clinical results. J Card Surg 1994;9:15-25.

17. Spotnitz HM, Hsu DT. Myocardial edema: importance in the study of left ventricular function. In: Karp RB, Laks H, Wechsler AS, editors. Advances in cardiac surgery. vol 5. St. Louis: Mosby; 1994. p. 1-25.

18. Mehlhorn U, Allen SJ, Adams DI, et al. Normothermic continuous antegrade blood cardioplegia does not prevent myocardial edema and cardiac dysfunction. Circulation 1995; 92:1940-6.

19. Baan J, Van der Velde ET, De Bruin HG, et al. Continuous measurement of left ventricular volume in animals and humans by conductance catheter. Circulation 1984;70:812-23.

20. Baan J, Van der Velde ET, Steendijk P, Koops J. Calibration and application of the conductance catheter for ventricular volume measurement. Automedica 1989;11:357-65.

21. Mirsky I. Assessment of diastolic function: suggested methods and future considerations. Circulation 1984;69:836-41.

22. Glower DD, Spratt JA, Snow ND, et al. Linearity of the Frank-Starling relationship in the intact heart: the concept of preload recruitable stroke work. Circulation 1985;71:9941009.

23. Glower DD, Spratt JA, Kabas JS, Davis JW, Rankin JS Quantification of regional myocardial dysfunction after acute ischemic injury. Am J Physiol 1988;255:H85-93.

24. Katus HA, Looser S, Hallermayer K, et al. Development and in vitro characterization of a new immunoassay of cardiac troponin T. Clin Chem 1992;38:386-93.

25. Gates RN, Laks H, Drinkwater DC Jr, et al. Can improved microvascular perfusion be achieved using both antegrade and retrograde cardioplegia? Ann Thorac Surg 1995;60:130811.

26. Gates RN, Lee J, Laks H, et al. Evidence of improved microvascular perfusion when using antegrade and retrograde cardioplegia. Ann Thorac Surg 1996;62:1388-91.

27. Weng Z-C, Nicolosi AC, Detwiler PW, et al. Effects of crystalloid, blood, and University of Wisconsin perfusates on weight, water content, and left ventricular compliance in an edema-prone, isolated porcine heart model. J Thorac Cardiovasc Surg 1992;103:504-13.

\section{Appendix}

Data were acquired with an IBM-compatible computer with an AD converting board (DAS-1601, Keithley Data Acquisition, Taunton, Mass.) at a sampling frequency of $200 \mathrm{~Hz}$. The time-varying conductance $\mathrm{G}(\mathrm{t})$ from the five intraventricular segments of the conductance catheter was recorded and summarized in the Leycom Sigma-5, giving the time-varying volume $\mathrm{V}(\mathrm{t})$ by the formula:

$$
\mathrm{V}(\mathrm{t})=[1 / \alpha]\left[\mathrm{L}^{2} / \sigma\right][\mathrm{G}(\mathrm{t})-\mathrm{Gp}]
$$

$\alpha$ is the "slope factor," which is the relation between the "true" and the conductance volume. The "true" volume (cardiac output) was measured by thermodilution. L is the distance between the electrodes on the catheter and $\sigma$ is the specific conductivity of the blood, which was measured in a cuvette before each set of volume recordings. Gp (the parallel conductance from structures surrounding the left ventricle), was calculated by a bolus injection of $4 \mathrm{ml} 10 \%$ hypertonic saline into the pulmonary artery. ${ }^{20}$ This was done at least three times after every set of measurements.

The PRSWA was defined as the area under the PRSW curve by the following formulas ${ }^{22,23}$ :

$$
\begin{gathered}
\mathrm{SW}=\mathrm{M}_{\mathrm{w}}\left(\mathrm{EDV}-\mathrm{V}_{0}\right) \\
\text { PRSWA }=1 / 2 \times \mathrm{M}_{\mathrm{w}}\left(1.2 \mathrm{~V}_{0 \max }-\mathrm{V}_{0}\right)^{2}
\end{gathered}
$$

$\mathrm{M}_{\mathrm{w}}$ is the slope of the PRSW and was calculated using linear regression. $V_{0}$ is the $\mathrm{x}$-axis (volume) intercept and $\mathrm{V}_{0 \text { max }}$ is the maximal $\mathrm{x}$-intercept value obtained over the entire experiment (68 $\mathrm{ml}$ in our study). EDV is enddiastolic volume and SW is stroke work.

$\beta$ was calculated by the following equation:

$$
\mathrm{EDP}=\alpha \times \mathrm{e}^{(\beta \times E D V)}
$$

where EDP is end-diastolic pressure, $\alpha$ is the $y$-axis intercept, and $\beta$ (unit less) describes the steepness of the curvilinear slope. However, the EDPVR could also be fitted to a straight regression line by the following equation:

$$
\mathrm{EDP}=\mathrm{E}_{\mathrm{ed}}\left(\mathrm{EDV}-\mathrm{V}_{\mathrm{d}}\right)
$$

where $\mathrm{E}_{\mathrm{ed}}$ is the slope of the EDPVR representing the left ventricular end-diastolic stiffness and $V_{d}$ is the $x$-axis (volume) intercept. 